\title{
Transient Neonatal Hypoparathyroidism
}

National Cancer Institute

\section{Source}

National Cancer Institute. Transient Neonatal Hypoparathyroidism. NCI Thesaurus. Code C114907.

A disorder of decreased production of parathyroid hormone by the parathyroid gland in a newborn. It is due to maternal hyperparathyroidism. It may be characterized by hypocalcemic seizures in the first weeks of life. 